\title{
Harnessing Mental Imagery and Enhancing Memory Specificity: Developing a Brief Early Intervention for Depressive Symptoms in Adolescence
}

\author{
Victoria Pile ${ }^{1}$ - Patrick Smith ${ }^{1} \cdot$ Mary Leamy $^{2} \cdot$ Abigail Oliver $^{1} \cdot$ Simon E. Blackwell $^{3} \cdot$ Richard Meiser-Stedman $^{4}$. \\ Barnaby D. Dunn ${ }^{5} \cdot$ Emily A. Holmes $^{6}$. Jennifer Y. F. Lau ${ }^{1}$ (1)
}

Published online: 16 August 2020

(c) The Author(s) 2020

\begin{abstract}
Background Treatment innovation for depressive symptoms in adolescence is urgently needed. Adult research suggests interventions targeting underlying cognitive mechanisms, such as dysfunctional mental imagery and overgeneral memory, are promising. Here, we describe and evaluate in a case series a brief imagery-based intervention for depressive symptoms that targets these cognitive mechanisms.

Methods Nine participants completed the four-session intervention, whose principle components were imagery rescripting and memory specificity training. Questionnaires and experimental tasks (assessing symptomatology and cognitive mechanisms) were administered at three time points: pre-intervention, post-intervention and 3-month follow-up.

Results The intervention was feasible to deliver and acceptable to participants. There was a large reduction in depression symptom scores from pre to post intervention $(\mathrm{d}=1.32 ; 67 \%$ showed reliable improvement, $\mathrm{RI})$ and this was maintained at follow-up $(\mathrm{d}=1.46 ; \mathrm{RI}=75 \%)$. There were also reductions in anxiety (post: $\mathrm{d}=1.15, \mathrm{RI}=44 \%$; follow-up: $\mathrm{d}=1.67$, $R I=63 \%$ ), increases in self-esteem (post: $d=-0.70, R I=44 \%$; follow-up: $d=-1.20, R I=50 \%$ ) and noteworthy changes in memory specificity (post: $d=-1.80, R I=67 \%$; follow-up: $d=-0.94, R I=63 \%$ ).

Conclusions This is the first study to use imagery rescripting and memory specificity training in adolescence. Initial evidence is provided that the intervention is acceptable and may have clinical utility. Future randomised controlled trials are needed to further assess the intervention.
\end{abstract}

Keywords Depression · Adolescence $\cdot$ Mental imagery $\cdot$ Autobiographical memory $\cdot$ Early intervention $\cdot$ Psychological therapy

Jennifer Y. F. Lau

jennifer.lau@kcl.ac.uk

1 Department of Psychology, Institute of Psychiatry, Psychology and Neuroscience, King's College London, De Crespigny Park, London SE5 8AF, UK

2 Florence Nightingale Faculty of Nursing and Midwifery, King's College London, London, UK

3 Mental Health Research and Treatment Center, Faculty of Psychology, Ruhr-Universität Bochum, Bochum, Germany

4 Department of Clinical Psychology and Psychological Therapies, Norwich Medical School, University of East Anglia, Norwich, UK

5 Mood Disorders Centre, University of Exeter, Exeter, UK

6 Department of Psychology, Uppsala University, Uppsala, Sweden and Division of Clinical Neuroscience, Karolinska Institutet, Stockholm, Sweden

\section{Introduction}

Depression in adolescence is common and impairing (Birmaher and Brent 2007; Cook et al. 2009). Adolescent depression is associated with psychological and social difficulties that often persist to adulthood, including higher social dysfunction, poorer academic performance and more physical ill health complaints (Andersen and Teicher 2008; Fombonne et al. 2001; Zisook et al. 2007). Early intervention that targets symptoms of depression may prevent these long-lasting and severe outcomes. Yet, current early interventions are rarely available (Health Committee 2014) and lack convincing evidence of effectiveness (Calear and Christensen 2010; Gee et al. 2020a, b). Utilising knowledge about which cognitive biases drive and maintain depression to develop new interventions offers promise to more effectively 
reduce depression (Dunn et al. 2019a, b; Holmes et al. 2018). Perhaps the most well replicated cognitive biases in depression are those in how autobiographical memories are represented, recalled and maintained (Dalgleish and WernerSeidler 2014). Autobiographical memory is important for the individual's sense of self, with adolescence being a time when self-concept develops and begins to consolidate (Conway and Pleydell-Pearce 2000; Kuyken and Dalgleish 2011). Indeed, recent advances in treatment development for adults have capitalised on findings that symptoms of depression are associated with dysfunctional mental imagery (of past memories and future events) and overgeneral memory (OGM) (Dalgleish and Werner-Seidler 2014; Holmes et al. 2016). As these cognitive mechanisms also characterise depressive symptoms in adolescence (Hitchcock et al. 2014; Pile and Lau 2018), targeting them could be a powerful and novel intervention approach.

\section{Emotional Mental Imagery}

Mental imagery occurs when perceptual information is accessed from memory (Kosslyn et al. 2001). It is similar to a form of weak sensory perception (Pearson et al. 2015), and can be associated with emotion. Emotional imagery has been associated with psychopathology, for example, both distressing intrusive negative memories and the absence of positive future images are implicated in depression (Holmes et al. 2016). Intrusions are very common in depression (44-87\% prevalence) and associated with severity across the age range (Meiser-Stedman et al. 2012; Williams and Moulds 2007; Williams et al. 2007). Imagery rescripting (IR) for negative intrusive images is a psychological approach with promising results in adults with depression (Brewin et al. 2009; Wheatley et al. 2007), with a meta-analysis indicating good effect sizes across disorders (Morina et al. 2017). Imagery rescripting employs psychological techniques (e.g. visualising an image in detail, identifying and updating the encapsulated meaning) to modify the content of distressing intrusive memories into more benign images (Morina et al. 2017). This seems particularly pertinent given evidence that, in adolescence, post-traumatic stress symptoms co-occur with depressive responses to non-traumatic negative life events and may maintain depression (Meiser-Stedman et al. 2012).

People with depression show a deficit in positive memories and in generating vivid positive future imagery (Holmes et al. 2016). Experimental evidence in adult community and dysphoric samples indicates that engaging in positive imagery (compared to verbal processing or negative/mixed valence imagery) can improve mood, interpretation bias and protect against subsequent negative mood (Blackwell and Holmes 2017; Holmes et al. 2006; Pictet et al. 2011; Renner et al. 2017). Similarly, in healthy adolescents, the generation of positive images can increase positive affect and reduce negative interpretation bias (Burnett Heyes et al. 2017). Studies targeting positive imagery in depressed adults show promise for reducing depressive symptoms (Ekkers et al. 2011; Korrelboom et al. 2012; Torkan et al. 2014), although a randomised controlled trial (RCT) using positive imagery-based cognitive bias modification indicated improvements in anhedonia but no advantage of the intervention compared to an active control for other depressive symptoms (Blackwell et al. 2015). This suggests that the generation of vivid positive imagery linked to image meaning, the self and to goals could be more effective in reducing depression than repeated generation of positive images. The application of IR to intrusive imagery and techniques to target positive future imagery have not yet been researched in young people with high symptoms of depression. These techniques may have trans-diagnostic targets. For example, having an excess of negative past images is also associated with anxiety (Hirsch et al. 2003; Morina et al. 2011) and imagery procedures have been successfully used to target self-esteem in depression (Korrelboom et al. 2012).

\section{Overgeneral Memory (OGM)}

OGM is a phenomenon where individuals have difficulty retrieving specific autobiographical memories and instead generate categorical or extended memories (Williams et al. 2007). OGM has been strongly implicated in depression, being not only associated with current symptoms but also with the onset and course of depression (Gibbs and Rude 2004; van Minnen et al. 2005). Two early-stage trials indicate that memory specificity training (MEST, generating specific memories to cue words e.g. happy) can reduce depressive symptomatology and improve day-to-day cognition in adolescents (Neshat-Doost et al. 2012) and female adults (Raes et al. 2009). However, a recent cluster-randomised controlled pilot trial with adults found no difference in depressive symptoms at 3-month follow-up between the group receiving MEST and an active control group (WernerSeidler et al. 2018). Recently, researchers have suggested that it could also be important for people to be able to flexibly shift between different categories of memories (Hitchcock et al. 2015, 2018) and so be able to hold specific memories alongside more general categories (for example values).

OGM and dysfunctional emotional mental imagery are inherently linked and likely to have a reciprocal relationship (please see Fig. 1 for a model integrating the intervention targets). OGM reflects difficulties in generating specific mental imagery, with many ascribing a central role of imagery-based processes in remembering specific autobiographical events (Conway and Pleydell-Pearce 2000; Holmes et al. 2016). Experimental studies have demonstrated this relationship, for example low imageable cues are associated with recall of more overgeneral memories than 


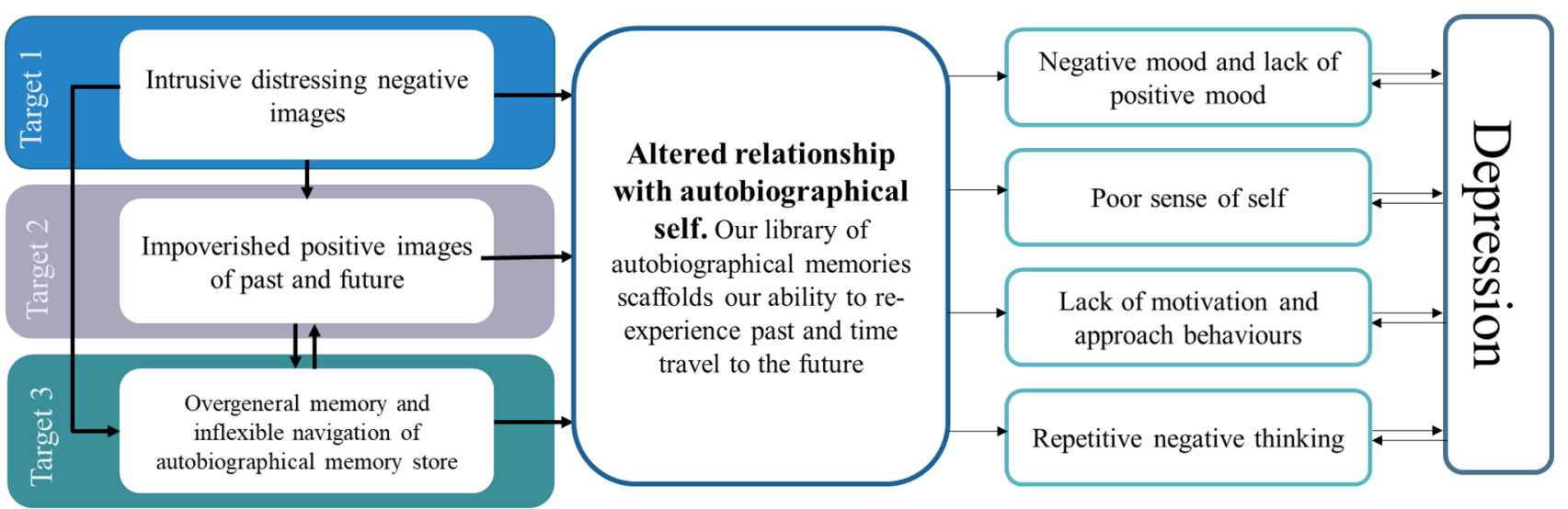

Key elements of the intervention:

Target 1: Targeted through imagery rescripting (session 2)

Target 2: Targeted through positive image generation (session 3)

Target 3: Targeted through MEST and values work (session 4 and homework)

Fig. 1 Model linking cognitive targets of the intervention with the experience of depression and the key aspects of the intervention that aim to ameliorate each cognitive target

high imageable cues (e.g. Rasmussen and Berntsen 2014). Greater avoidance of intrusive negative memories/images is thought to be a key factor in increasing OGM, so IR (which targets negative images and the avoidance of them) may also decrease OGM. Similarly, autobiographical memory scaffolds our ability to imagine our future, with a marked overlap in brain activity for remembering memories and imaging future events (e.g. Anderson et al. 2012; Schacter et al. 2007). For example, more detailed future events are generated following an experimentally induced specific compared to general retrieval style (e.g. Madore et al. 2014; Williams et al. 1996). Targeting emotional mental imagery and OGM are highly complementary and, consistent with the combined cognitive bias hypothesis (Hirsch et al. 2006), may influence each other to maintain symptoms of depression. Using IR and MEST in combination may target dysfunctional mental imagery and OGM more powerfully than either used in isolation.

\section{Developing an Early Intervention for Symptoms of Depression in Adolescence}

Current interventions tend to be costly and difficult to widely distribute. Short duration interventions that can be readily and widely deployed are essential to address this area of need. A recent UK government green paper highlighted the importance of young people who show early signs of distress being able to access appropriate help, and that schools should be central in efforts to prevent problems deteriorating (Secretary of State for Health and Secretary of State for Education 2017). Early interventions in schools commonly employ components of Cognitive Behavioural Therapy
(CBT) with indicated programs (targeting individuals with depressive symptoms) being slightly more effective than alternative programs (e.g. targeting all students or those with risk factors) (Calear and Christensen 2010; Werner-seidler et al. 2017).

In the current study, we have developed a brief manualised early intervention for depressive symptoms that can be delivered in schools. Translating findings from cognitive science into clinical interventions could take a number of approaches. One approach is to only target the key cognitive process (e.g. memory specificity) to reduce complexity. Whilst these interventions have tended to successfully modify the targeted mechanism, they have been less successful in reducing depressive symptoms compared to a control group (e.g. Werner-Seidler et al. 2018). Another approach (and the one adopted here) is to develop a complex intervention, which have several interacting components and techniques to target the proposed mechanisms (Craig et al. 2008). These are more common in clinical practice. The complex intervention developed here combined psychological techniques of IR and MEST to target dysfunctional autobiographical memory processes (distressing negative images, impoverished positive future images and overgeneral memory; Fig. 1). Some additional techniques supplemented IR and MEST to optimise their effectiveness, for example we included work identifying values to generate categories of specific memories.

Here, we report on preliminary findings from nine young people. The aims of this study were to (1) provide a preliminary test of the intervention, in terms of feasibility and acceptability, to refine the protocol; (2) to establish proof of concept for the intervention by (a) showing no evidence of 
harm and (b) some evidence of clinical gain (and changes in targeted cognitive mechanisms) immediately following the intervention and at 3-month follow-up. Symptoms of depression and anxiety will be measured as well as post-traumatic stress symptoms (given that IR is targeting intrusions and associated post-traumatic stress symptoms in response to negative life events). As our focus is on dysfunctional autobiographical memory processes and their links with sense of self, we will also measure self-esteem and self-concept clarity. In addition, participants completed daily ratings to provide real-time repeated sampling of current mood and social connectedness in their natural environment (Wenze and Miller 2010). The feasibility of completing these daily ratings, and changes following intervention, is also recorded. This study is the first step in evaluating this intervention, allowing assessment of whether a feasibility trial is warranted and to aid the planning of such a trial. Early stage case series, such as this one, provide a resource and timeefficient approach to iteratively refine the protocol before proceeding to a more resource intensive RCT.

\section{Materials and Methods}

\section{Design and Procedure}

A single case series design was used, consistent with similar previous research (Ritter and Stangier 2016). This consisted of three phases in an A-B-A design. For this design, participants were identified as those scoring above clinical cut-off on a measure of depression and assigned to a no-intervention phase of 2 weeks. No intervention or discussion of mental health took place during this period. Next, they received the intervention consisting of four ninety-minute intervention sessions. When the participants had completed the intervention, they were followed up for 3 months, in which no further intervention was administered. Participants completed assessment before and after the intervention and 3 months following completion of the intervention.

This sample size is consistent with similar studies (Brewin et al. 2009; Dunn et al. 2019a, b; Frets et al. 2014; Ritter and Stangier 2016) and was chosen to reflect our primary aim of providing an initial assessment of feasibility and acceptability, rather than being powered for statistical significance testing. Schools were approached, and pupils aged 16-18 invited to complete screening. Pre-intervention assessment was completed 2 weeks after screening and only participants scoring above cut-off at both were invited to complete the intervention. This assessment included a clinical interview to assess risk and to check inclusion/exclusion criteria. To ensure regular intervention sessions, the project was designed to be completed within a school term. The assessment and all intervention sessions took place in a small quiet room within each school over the course of the school day. In this paper, we report how we determined our sample size, all data exclusions (if any), all manipulations, and all measures in the study (Simmons et al. 2012).

\section{Participants}

Nine young people (six females; mean age $=16.95$; $\mathrm{SD}=0.54$; range $=16.18-17.86 ; 56 \%$ White British or White European) from two secondary schools in London, UK took part in the project. There were four participants from one school (ID1-4) and five from another (ID5-9). The Psychiatry, Nursing and Midwifery Research Ethics Committee at Kings College London (ref: HR-16/17-3548) gave ethical approval. All participants provided written informed consent. Inclusion criteria included: aged 16-18 and scoring above cut-off for depression. Exclusion criteria included: diagnosis of learning disability; high levels of risk; currently receiving another psychological intervention (including school counselling); experiencing distressing psychotic symptoms. Three participants (ID2, 3, 8) reported having mental health diagnoses (major depressive disorder, bulimia nervosa and post-traumatic stress disorder) and past psychological intervention (all had received a minimum of 2 years of psychotherapy).

\section{Measures}

\section{Feasibility and Acceptability}

Recruitment and retention rates were recorded throughout, including number of schools contacted; number completing the screening questionnaire and scoring above cut-off; number invited and willing to take part; number of participants completing pre, post and follow-up assessments with reasons for drop-out. To measure acceptability, participants completed a feedback questionnaire, which included rating scales and written responses. Three rating scale questions asked about: overall satisfaction, how much the intervention had helped them and whether they would recommend it. Participants were asked to respond using a five-point Likert scale, from one being a negative response (e.g. "very dissatisfied') to five being a positive response (e.g. 'very satisfied'), and three being a neutral response (e.g. 'neither satisfied or dissatisfied'). A final question asked about the number of sessions, with a rating of three being "I was happy with the number of sessions'; one and two indicated preferring fewer sessions ( 1 being ' $2+$ less' and 2 being ' $1-2$ less') and 4 and 5 preferring more sessions ( 4 being ' $1-2$ more' and 5 being ' $2+$ more'). Adverse events, concerns 
about risk or change in symptoms/distress were recorded throughout as indicators of harm.

\section{Symptom Measures}

The Mood and Feelings Questionnaire (Angold et al. 1995) (MFQ) was used to measure depression and was the primary outcome for the intervention. Following a discussion with our ethics committee, four items pertaining to risk from the long version of the MFQ were removed due to ethical considerations for group testing (risk was instead assessed by a clinical interview in the initial assessment). A clinical cut-off score of 20 on the MFQ was employed consistent with similar studies (Smith et al. 2015; Wright et al. 2014) and so, given the removal of items, a cut-off of 17 was used in this study. The Short MFQ (12 items) was administered at the beginning of each intervention session. The Screen for Child Anxiety Related Disorders (Birmaher et al. 1997) (SCARED) was used to measure anxiety and the Child Revised Impact of Event Scale (Perrin et al. 2005) (CRIES) measured post-traumatic stress symptoms (PTSS) in reference to a negative event. The Rosenberg Self Esteem Scale (Rosenberg 1965) (RSES) measured self-worth.

\section{Measures of Cognitive Processes}

The adult version of the Prospective Imagery Task (Holmes et al. 2008; Stober 2000) (PIT) was adapted for use in young people (Pile and Lau 2018) to measure vividness of positive and negative future images. Adaptations included reducing the number of items to seven for each subscale and modifying some of the language. The Autobiographical Memory Task (Williams and Broadbent 1986) (AMT) was administered to measure memory specificity to ten cue words (five positive; five negative). In the current study, inter-rater consistency was excellent (93\% agreement). The Self-Concept Clarity scale (Campbell et al. 1996) (SCCS) was used to measure the participant's confidence in being able to define themselves clearly. The Children's Response Style Questionnaire (Abela et al. 2004) (C-RSQ) measured cognitive responses to low mood, with three subscales: ruminative responses; distracting responses; and problem-solving responses. As response styles were not directly targeted in the intervention, this was included to assess whether changes in cognitive mechanisms were unique to those targeted.

A novel Memory Recall Task measured participants' emotional response to a positive memory pre-intervention and a matched memory post-intervention (adapted from Gadeikis et al. 2017). Emotional response was measured using subjective ratings of mood before and after recall, where participants were asked to rate four subscales for positive affect (happy, joyful, excited, energetic) and four for negative affect (sad, angry, nervous, and upset) on a Likert scale from 1 (not at all) to 9 (extremely). This was administered using the software package, PsychoPy.

\section{Daily Ratings}

Participants were asked to complete daily ratings of mood and social connectedness for 1 week before and after the intervention. They are asked to rate positive and negative affect (using same scales as above) and to specify who they were with each day at $6 \mathrm{pm}$ using a mobile phone app. The memory recall task and daily ratings were not included at follow-up to limit burden on participants.

\section{Intervention}

The intervention was delivered by the first author (Clinical Psychologist) with the second author providing clinical supervision (Consultant Clinical Psychologist). The intervention was aimed to be delivered weekly and consist of four sessions, lasting up to $90 \mathrm{~min}$. The intervention combined (a) imagery rescripting (IR) to reduce the distress associated with a negative image and to build a positive future image (adapted from Holmes et al. 2019); and (b) memory specificity training (MEST) to increase specificity and access to memories (adpated from Hitchcock et al. 2018; Raes et al. 2009). We adopted an integrative approach to development and the manualised intervention used cognitive behavioural procedures (e.g. an agenda and homework) and was accompanied by worksheets. All imagery exercises were completed in the first person, present tense and (when happy to) participants were asked to close their eyes. Participants were asked to generate as much detail as possible and were prompted for additional sensory information as well as for thoughts, feelings and the meaning of the image to them. These exercises aimed to target emotional mental imagery and concurrently increase specificity of these memories (see Table 1 for an overview of the exercises and homework). Homework tasks were delivered via a mobile phone application, which the participants downloaded onto their phones and prompted them to complete the task at $6 \mathrm{pm}$ each evening.

The format and length of the intervention was generated by focussing on one target per session plus a summary session. We aimed to design a brief intervention, given evidence that longer courses of treatment do not necessarily produce better results (Calear and Christensen 2010); cost implications for longer interventions; practical considerations for future implementation in schools (Gee et al. 2020a, b); and given preferences from lived experience representatives for brief and clearly packaged interventions. The main aims of session 1 were to provide a rationale for 'training memories' and develop a positive past memory. The rationale includes concepts such as: memories competing with one another for 
Table 1 Overview of exercises and homework tasks in the intervention

\begin{tabular}{lll}
\hline & Exercise & Procedure \\
\hline Session 1 & Recall positive past memory & $\begin{array}{l}\text { Relive positive past memory in detail, identifying sensory components as } \\
\text { well as feelings, thoughts, behaviour and the meaning of the image to the } \\
\text { individual } \\
\text { Examples }\end{array}$ \\
& $\begin{array}{l}\text { Going to a theme park with friends } \\
\text { Being greeted by family after returning home from a trip away }\end{array}$
\end{tabular}

Session 2 Imagery rescripting for a negative past image

(1) Relive image at the age of the participant when the event took place and to provide specific details about the memory. The meaning and significance of this image is discussed with the participant

(2) Relive image as a compassionate other who is able to intervene. Participants are asked to identify a kind, compassionate adult in their lives who they then imagine intervening during the imagery

(3) Relive image as themselves but with the intervention from the compassionate other

Examples

Finding out that they had failed an exam (associated meaning: I'm a failure; I have let my parents down)

Incident where the participant was called a derogatory term by a peer (associated meaning: I'm not good enough; I'm weird)

Session 3 Generating a positive future image

(1) Imagine a vivid positive future image, which is specific and rich in sensory detail

(2) Imagine that they have achieved this future goal (future me) and speak to their current self (current me) to offer advice, speak about what has been good and what has been difficult and what has helped them achieve their goal

(3) Beginning from their current self they imagine the steps to reach their future self

Examples

Studying at university (being in a university lecture)

Success in their chosen career (being in an art studio surrounded by their work)

Fourth session Link specific memories to general categories

(1) Values for living are discussed to generate categories that are important to the participant

(2) The specific memories that the participants have generated over the last four sessions (both via the app and in session) are reviewed and it is discussed how the memories relate to these categories

Homework Memory specificity training (MEST; week 1-3) A cue word (e.g. music) is sent each day and participants are asked to respond with a specific memory. In week 1 and 2 , these were positive and neutral words. In week 3, participants were given two cue words per day (one positive and one negative) which are the opposite of one another (e.g. accepted; judged)

Positive data $\log ($ week 2 and 3)

Participants are asked to record something positive that had happened to them that day

retrieval (Brewin 2006); the encapsulated meaning of memories; and the relationship between memories, mood and behaviour. A rationale for each exercise is also given each session. The focus for session two is negative past images, targeted using IR. The procedure was adapted for adolescents based on previous adult literature (Frets et al. 2014; Wild and Clark 2011; Wild et al. 2008). In session 3, the emphasis is on positive future images. The procedure was developed based on experimental literature (Werner-Seidler and Moulds 2012) and the principles for negative imagery rescripting to enhance generalisation of the techniques. The focus of the final session is to review the intervention, link their specific memories to more general categories and to consider how to use the strategies in the future.

\section{Data Analysis}

Feasibility and acceptability data are presented descriptively. Descriptive statistics are reported for measures of symptomatology and cognitive mechanisms at each time-point. This descriptive data will be reviewed for each participant to observe any changes from pre to post intervention and whether these changes appear to be maintained at followup. To reduce the chances of making biased interpretations of any changes in outcome measures, additional measures of change were calculated: effect sizes and reliable change (RC). Formal statistical testing was not conducted due to the small sample size. Within group effect sizes were estimated using Cohen's d to provide an indication of whether there was change with the intervention (although interpretation 
is limited by potential confounding). Effect sizes for pre to post-intervention and pre-intervention to follow-up were calculated using the formula: Cohen's $d=\left(\mathrm{M}_{\mathrm{PRE}}-\mathrm{M}_{\mathrm{POST} / \mathrm{FU}}\right) /$ $\mathrm{SD}_{\mathrm{PRE}}$ based on previous literature (Cohen 1988; Ritter and Stangier 2016). This means that negative effect sizes indicate an increase in scores from pre to post/follow-up and positive effect sizes represent a decrease in scores. The number of participants that showed RC was also calculated (Jacobson and Truax 1991), operationalised using Morley and Dowzer (2014) guidelines. Reliability estimates for each scale were extracted from previous publications (Abela et al. 2004; Birmaher et al. 1997; Bos et al. 2010; Campbell et al. 1996; Kuyken et al. 2006; Perrin et al. 2005; Pile and Lau 2018; Wood et al. 1995). RC is found when the magnitude of change (either improvement or deterioration) is more than can be explained by measurement error, calculated using an excel application (Morley and Dowzer 2014). Participants were allocated to three outcome categories "yes" when reliable improvement (RI) is observed, "no" when no RC is indicated and "deteriorate" when participants show reliable deterioration (RD) in their scores.

For the memory recall task and daily ratings, data completeness provided an indication of feasibility and mean positive and negative affect were calculated from combining scores from the four subscales. Change in affect with recall was calculated (rating provided after recall minus the rating before recall) to understand whether the task worked as a positive mood induction in this population. For the daily ratings, an average affect score across the week was calculated for each participant. RC will not be calculated for these measures as there are no pre-existing estimates of reliability.

\section{Results}

\section{Feasibility and Acceptability}

School recruitment (i.e. identifying schools that were willing to take part and had appropriate facilities) took place in term 1. Eight schools were contacted by email and two responded. Screening, pre and post assessment and intervention all took place in term 2 with 3 -month follow-up being completed in term 3. 114 participants completed the MFQ, 25 of these participants scored above clinical cut-off and were contacted to take part in the intervention. Ten participants responded to this invitation. Of the remaining fifteen, the contact details were incorrect for three participants and the 12 participants did not respond to the invitation and no reasons were given for not wanting to take part. Comparing those who did and did not respond on screening data, there did not appear to be any differences in terms of age (response: $\bar{x}=17.12$; no response: $\bar{x}=17.70, \mathrm{p}=0.19$ ), gender (response: seven females; no response: ten females, $\mathrm{p}=0.86$ ) or depression score at screen (response: $\bar{x}=28.30$; no response: $\bar{x}=27.40$, $\mathrm{p}=0.80$ ). At first assessment, one participant was not eligible as they were receiving school counselling, leaving a final sample size of nine participants. These participants completed all measures at all assessment time points, expect one participant (ID7) who did not complete the follow-up assessment as they had graduated from school.

In terms of compliance, all participants completed all four sessions and engaged well in the intervention. On the homework tasks, compliance was mixed (see Table 2). For completing a specific memory on the app each day (MEST, total number of days $=21$ ), six participants completed more than 18 days (86\%) with two participants completing only 1 or 2 days. The app for the homework tasks did not work on one participant's phone (ID2) and therefore this participant completed the homework tasks by pen and paper. For the positive data $\log$, compliance was very similar, with five participants completing at least $86 \%$ of days and three not completing any days.

Acceptability was measured by the feedback questionnaire (see Table 3). Overall, participants were satisfied with the intervention $(\bar{x}=4.22 ; \mathrm{SD}=0.44)$, felt that the intervention helped them $(\bar{x}=4.22 ; \mathrm{SD}=0.44)$, and would recommend it to a friend $(\bar{x}=4.67 ; \mathrm{SD}=0.50)$. Seven of the nine participants were "happy with the number of sessions" whilst two participants stated that they "would have liked 1-2 more". Themes were identified from written responses in the feedback booklet. One theme was that the intervention improved mood and provided strategies to reduce low mood. Another theme was the importance of the memory work, identifying important elements as being able to cope and face bad memories and to use positive memories to improve mood. In terms of completing the programme at school, most participants felt that this was positive, using

Table 2 Homework compliance: number of days that participants responded with specific memories to cue words (MEST) and the number of days that participants completed the positive data $\log$

\begin{tabular}{|c|c|c|c|c|c|c|c|c|c|c|c|c|}
\hline \multirow[t]{2}{*}{ Intervention compliance } & & \multicolumn{9}{|c|}{ Participant number } & \multirow[t]{2}{*}{ Mean } & \multirow[t]{2}{*}{$\mathrm{SD}$} \\
\hline & & 1 & 2 & 3 & 4 & 5 & 6 & 7 & 8 & 9 & & \\
\hline \multirow[t]{2}{*}{ Number of days completed } & MEST (total = 21) & 20 & Completed on paper & 2 & 19 & 21 & 18 & 1 & 20 & 21 & 15.25 & 8.55 \\
\hline & Positive data $\log ($ total $=14)$ & 12 & & 0 & 14 & 14 & 0 & 0 & 14 & 14 & 8.50 & 7.07 \\
\hline
\end{tabular}


Table 3 Quantitative feedback on the acceptability of the intervention

\begin{tabular}{|c|c|c|c|c|c|c|c|c|c|c|c|}
\hline \multirow[t]{2}{*}{$\overline{\text { Questions }}$} & \multicolumn{9}{|c|}{ Participant number } & \multirow[t]{2}{*}{ Mean } & \multirow[t]{2}{*}{$\mathrm{SD}$} \\
\hline & 1 & 2 & 3 & 4 & 5 & 6 & 7 & 8 & 9 & & \\
\hline Overall, how satisfied are you with the programme? & 4 & 4 & 5 & 5 & 4 & 4 & 4 & 4 & 4 & 4.22 & 0.44 \\
\hline To what extent has the intervention helped you? & 4 & 4 & 4 & 5 & 4 & 4 & 4 & 5 & 4 & 4.22 & 0.44 \\
\hline Would you recommend the intervention to a friend? & 5 & 5 & 5 & 4 & 4 & 5 & 5 & 5 & 4 & 4.67 & 0.50 \\
\hline $\begin{array}{l}\text { What did you think about the number of sessions in } \\
\text { the intervention? Alterative scale used }\end{array}$ & 3 & 3 & 3 & 4 & 3 & 3 & 3 & 4 & 3 & 3.22 & 0.44 \\
\hline
\end{tabular}

The scales are 1-5 with 5 being the most positive answer (e.g. very satisfied) unless otherwise specified

${ }^{a}$ For this scale, 3 is the most positive answer indicating that they are happy with the number of sessions. 1 and 2 indicate preference for fewer sessions and 4 and 5 indicate preference for more sessions words such as 'convenient' and 'comfortable'. In terms of responses that would suggest changes to the methodology or intervention, one participant said that it was tiring to complete the intervention after school and another reported finding it stressful to have to complete two cue words in a day (in week 3).

\section{Changes in Symptomatology}

Depression scores (measured by the MFQ) from screening and pre-intervention assessment were compared to see whether there were indications of change during this 2-week period. There was little change in scores $(\mathrm{d}=0.16$, according to Cohen's rules of thumb, Cohen 1988) with one participant showing RI and one participant showing RD.

In terms of within subject effect size, a large effect from pre to post $(\mathrm{d}=1.32)$ and from pre to follow-up $(\mathrm{d}=1.46)$ was observed. Descriptively, all nine participants showed a decrease in depressive symptoms from pre to post (six showing RI, 67\%). Seven out of eight showed a decrease in depressive symptoms from pre to follow-up (six showing RI, $75 \%$ ) and one showing RD in depressive symptoms. Six of nine at post, and six of eight participants at follow-up were below the clinical cut-off score on the MFQ. See Table 4 for individual changes in symptoms. On the short MFQ administered each session, there appears to be a steady decline in symptoms of depression each session for most participants with a slightly larger decrease from session one to two (see Fig. 2).

In terms of anxiety measured by the SCARED, the within-subject effect sizes indicated a large decrease in symptoms from pre to post $(\mathrm{d}=1.15)$ and from pre to follow-up $(d=1.67)$. Seven (of nine) participants showed a decrease in anxiety pre to post (four showing RI, 44\%). All eight showed a decrease in anxiety pre to follow-up (five showing RI, 63\%). With respect to PTSS measured by the CRIES, the effect size indicated a small reduction from pre to post $(\mathrm{d}=0.38)$ and a large reduction from pre to follow-up $(d=1.59)$. Six (of nine) participants showed a decrease in PTSS pre to post (one showing RI, 11\%). Seven (of eight) showed a decrease in PTSS pre to follow-up (four showing RI, 50\%). Higher self-esteem is represented by a higher score on the RSES. The within-subject effect sizes indicated a medium increase from pre to post $(\mathrm{d}=-0.70)$ and a large improvement from pre to follow-up $(\mathrm{d}=-1.20)$. Eight (of nine) participants showed an increase in self-esteem pre to post (four showing RI, 44\%). Seven (of eight) showed an increase in self-esteem pre to follow-up (four showing RI, $50 \%$ ). One participant (ID = 1) showed RD in self-esteem from pre to post, however this participant showed a reliable increase in their self-esteem from pre to follow-up.

\section{Changes in Cognitive Mechanisms}

The prospective imagery task (PIT) measured future image vividness. In terms of effect sizes, there was a small increase in positive image vividness (pre to post, $\mathrm{d}=-0.46$; pre to follow-up, $\mathrm{d}=-0.40$ ) and a large decrease in negative future imagery vividness from pre to post $(\mathrm{d}=1.01)$ with a medium pre to follow-up change $(\mathrm{d}=0.56)$. For positive image vividness, seven (of nine) participants showed increases pre to post (three showing RI, 33\%) and four (of eight) showed increases pre to follow-up (two showing RI, 25\%). For negative image vividness, seven (of nine) participants showed decreases pre to post (three showing RI, 33\%) and four (of eight) showed decreases pre to follow-up (two showing RI, $25 \%$ ). See Table 5 for individual changes in scores.

With respect to memory specificity measured by the AMT, there was a large increase in terms of effects sizes from pre to post $(\mathrm{d}=-1.80)$ and from pre to follow-up $(d=-0.94)$, indicating that the specificity in which young people recalled autobiographical memories may increase with the intervention. All nine participants showed increases in memory specificity pre to post (six showing RI, 67\%) and seven (of eight) showed increases pre to follow-up (five showing RI, 63\%). In terms of self-concept clarity as measured by the SCCS, overall there was a medium effect size (increase) from pre to post $(\mathrm{d}=-0.75)$ and a large effect from pre to follow-up $(\mathrm{d}=-1.13)$ in how confident participants felt in being able to clearly define themselves. 


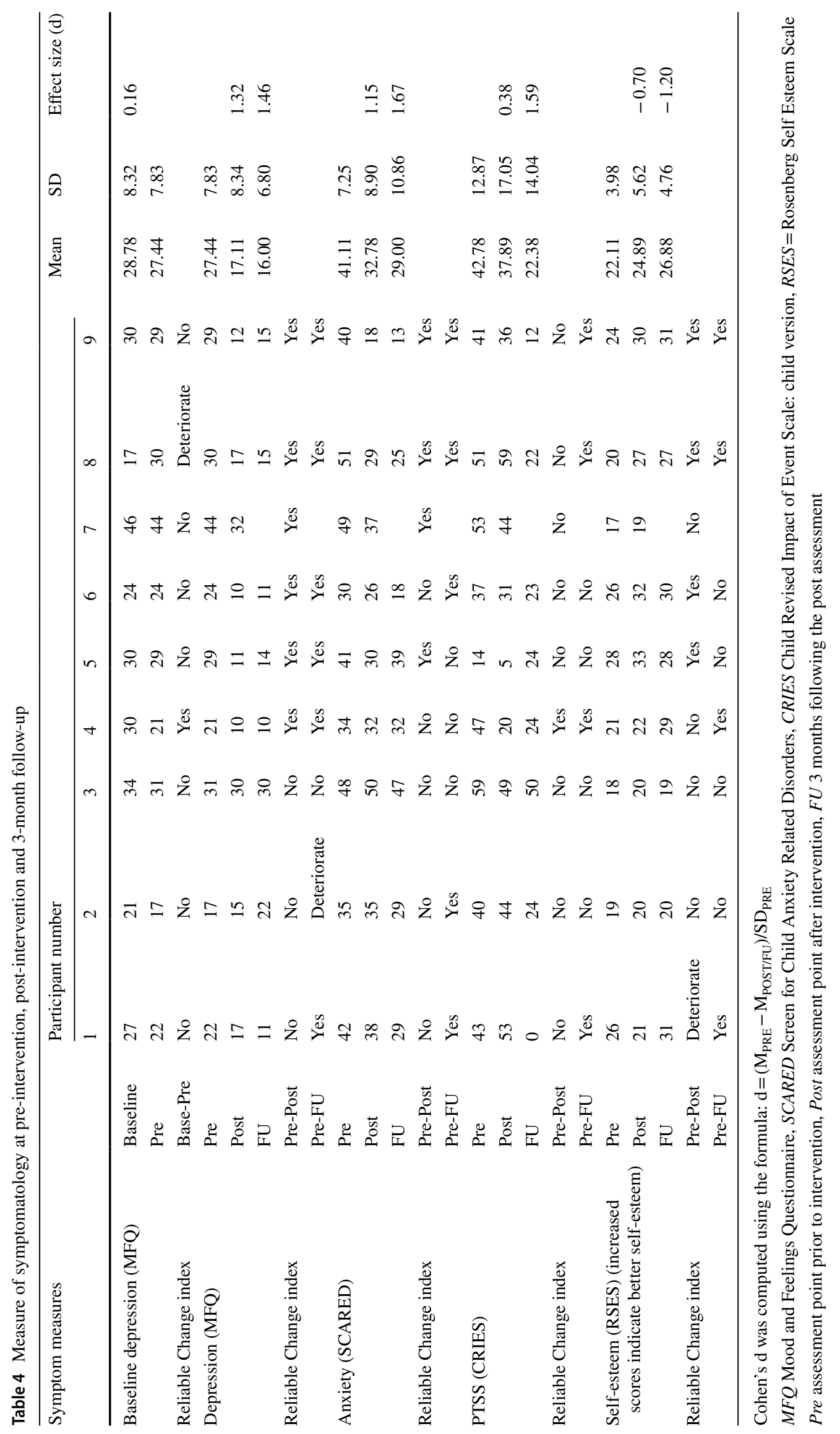




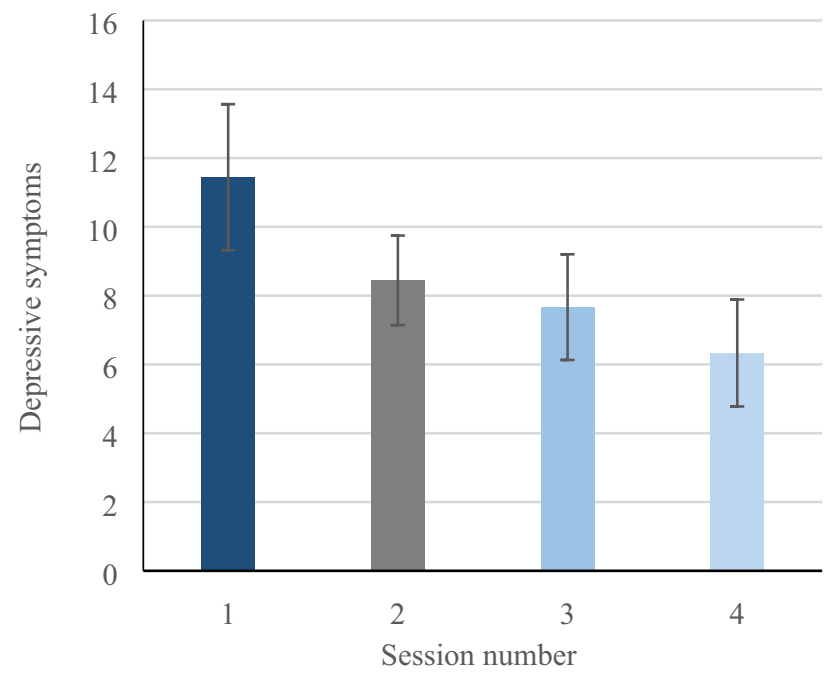

Fig. 2 Change in depressive symptoms across intervention sessions as measured by the Short MFQ

Seven (of nine) participants showed increases in SCC pre to post (four showing RI, 44\%) and seven (of eight) showed increases pre to follow-up (five showing RI, 63\%). In terms of mechanisms not directly targeted by the intervention, all changes on the measures of cognitive responses to low mood (rumination, distraction and problem solving measured using the CRSQ) were small (with no more than two participants showing RC on any of the subscales).

All participants agreed to complete the memory recall task and submitted two positive memories before attending the assessment, suggesting the task is feasible in this context. In terms of change in affect (see Table 6), the memory recall task appeared to induce the intended affective experience: positive affect increased (change in pre ratings: $\bar{x}=0.53$; $\mathrm{SD}=1.77$; change in post ratings: $\bar{x}=0.47 ; \mathrm{SD}=0.64$ ) and negative affect decreased (pre: $\bar{x}=-1.08 ; \mathrm{SD}=1.21$; post: $\bar{x}=-0.64 ; \mathrm{SD}=0.71)$. However, there was no evidence of enhancing this change with intervention (positive affect: $\bar{x}$ $=-0.056 ; \mathrm{SD}=1.83$; negative affect $\bar{x}=0.44 ; \mathrm{SD}=0.82$ ).

\section{Daily Ratings of Mood and Social Connectedness}

Mean completion rates pre-intervention were $6.67(\mathrm{SD}=0.5)$ with all participants completing at least 6 days of ratings (see Table 7). At post-intervention, mean completion was 4.00 (2.96), with four participants completing at least 6 days and four completing 2 or less days. Overall there was a small $(d=-0.27)$ increase in positive mood and a small $(d=0.49)$ decrease in negative mood from pre to post time points. Changes in mood ratings were mixed across the group with five of eight participants reporting increases in positive mood and five of eight reporting decreases in negative mood. In terms of social connectedness, the percentage of time spent alone appeared to decrease following the intervention (52\% pre to $39 \%$ post intervention). However, given the low post-intervention completion rates and variability across participants, this data should be interpreted with caution.

\section{Discussion}

The present study is the first investigating the use of IR combined with MEST in young people with symptoms of depression. Conducting this intervention with nine participants provides initial evidence that this approach could be a feasible and useful early intervention for depressive symptoms. Overall, $67 \%$ of participants showed reliable improvements in depressive symptoms (as measured by the MFQ) and this change was maintained 3 months later (RC: $75 \%$ ). There were also improvements in anxiety (RC: $44 \%$ at post and $63 \%$ at follow-up) and self-esteem (RC: $44 \%$ at post and $50 \%$ at follow-up). The intervention is consistent with current UK government initiatives to provide early intervention for mental health in schools (Secretary of State for Health and Secretary of State for Education 2017).

In terms of our first aim to provide an initial test of feasibility and acceptability, participants were willing to take part, and to complete the intervention and outcome measures. Retention from pre to post assessment was 100\% and the entire case series (beginning recruitment to 3-month follow-up) was completed within a school year. Twenty-five participants were invited to take part, but the contact details were incorrect for three participants. Ten of twenty-two (45\%) participants responded to the invitation to take part, consistent with similar studies (Smith et al. 2015). Indeed this mirrors findings that young people are reluctant to seek help, with estimates that only $18-34 \%$ of young people with high levels of depression or anxiety will seek help (Gulliver et al. 2010). From the literature (e.g. Gulliver et al. 2010) and in discussion with our lived experience representatives, possible reasons for the remaining twelve participants not responding include not receiving the invitation (e.g. going into their junk folder); fears about confidentiality; concerns about what taking part involves (e.g. time commitment; psychological testing); believing that the intervention would not be of benefit to them.

In terms of acceptability, participants reported being satisfied with the intervention, that it had helped them, would recommend it to a friend and were happy with the number of sessions. This suggests that the intervention and trial design are feasible and acceptable. There were some changes suggested by the feedback which will be implemented for a future RCT, including not having two memories to complete each day in the homework tasks and where possible arranging sessions within the school day. Compliance with the homework and daily mood ratings 


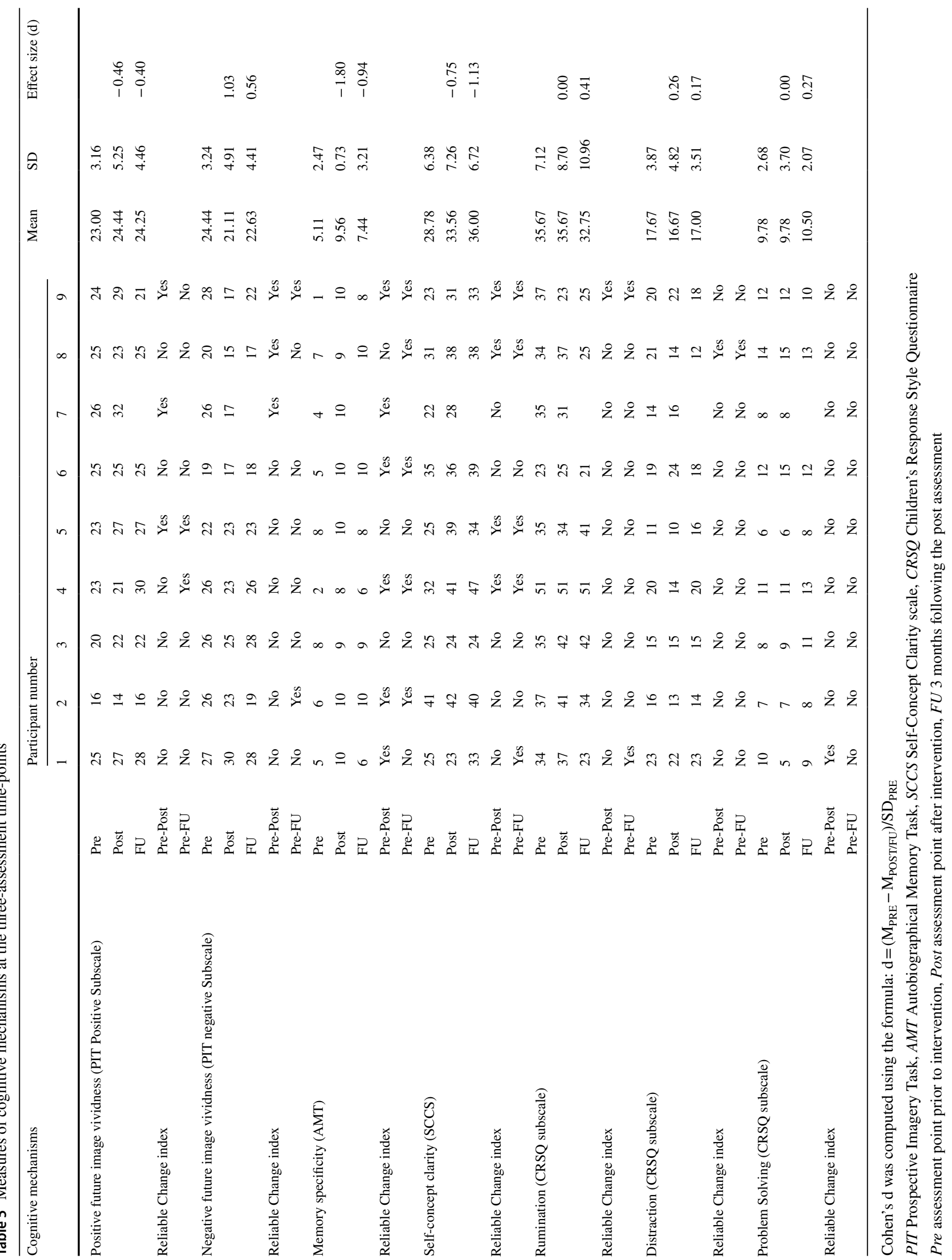


was mixed; the main reason provided was forgetting to complete it and so the inclusion of prompts is indicated. There were also technical issues with one of the phones and so it will be important to ensure that alternative arrangements are possible in a future trial.

Our second aim was to establish proof of concept. We first hoped to show no evidence of harm (i.e. no marked deterioration or adverse events that were clearly treatment related). One participant (ID2) showed deterioration in depression scores from pre to follow-up. Follow-up assessment took place before the summer holidays and this participant reported feeling concerned and hopeless about having to be at home with her parents for an extended period (she did not live at home during term time). This deterioration is therefore highly unlikely to be associated with the intervention and this participant did not show deterioration on other measures.

Secondly, we hoped to show some evidence of clinical gain. Across participants, this case series indicated a tenpoint decrease on the depression measure (MFQ), which previous studies have identified as clinically meaningful (Smith et al. 2015) as well as improvements in anxiety and self-esteem. A meta-analysis of indicated school-based interventions found a small effect on reducing symptoms of depression (standardised mean difference $=0.34$ ), compared to a control group (Gee et al. 2020a, b). Whilst the effect sizes obtained here (1.32 at post and 1.46 at follow-up) are not relative to a control, and thus cannot be compared to between-group meta-analytic effect sizes, their magnitude is promising. Whilst it is important not to overinterpret this finding given the small sample, possible reasons for these larger effects include because the intervention was grounded in cognitive science, which has been suggested to potentially lead to more effective interventions (Dunn et al. 2019a, b; Holmes et al. 2018); because it harnessed mental imagery which is thought to be more powerful than verbal approaches (Burnett Heyes et al. 2013; Holmes et al. 2016); and/or that the intervention is brief, focussed and structured which, in our clinical experience, can often be more acceptable to adolescents and more effective.

A key aim of the intervention was to target underlying cognitive mechanisms that drive depression, which the findings provided mixed support for. As predicted, there were noteworthy changes in memory specificity and self-concept clarity. There are well-established relationships between depression and memory specificity (Hitchcock et al. 2014) as well as depression and self-concept clarity (Chang 2001) and so it is encouraging that the intervention led to changes in these cognitive processes as these were some of the central targets for the intervention. However, whilst memory specificity did improve from pre to follow-up intervention $(d=-0.94)$ the improvement from pre to post intervention was considerably larger $(\mathrm{d}=-1.80)$. Whilst we should be cautious in over interpreting this as meaningful, it might suggest that some of the training effects on memory specificity might be lost over time without specific prompts to practice. Future studies might include ways of reminding participants to practice recalling specific memories.

It was perhaps surprising that there that there were not more participants showing reliable change in positive and negative prospective imagery vividness. Overall the direction of change for future imagery vividness (increase in positive, $\mathrm{d}=-0.46$, and decrease in negative, $\mathrm{d}=1.03$ ) was consistent with our aims. Whilst these effect sizes are encouraging, few of the participants demonstrated reliable change (only three of nine). Similarly, there was little change observed in ability to increase positive affect and decrease negative affect using a positive autobiographical memory following intervention. This lack of reliable change could be due to the questionnaire and task used (e.g. the same questionnaire items and task were used at the assessments) or that participants are able to vividly picture events when asked but don't employ this as a strategy in everyday life. In contrast to these findings, qualitative feedback highlighted the importance to participants of being able to use memory strategies to regulate emotion, so it might be that the tasks don't capture some of the changes participants value. It may also be the intervention could be adjusted to further promote vivid imagery (especially for those with lower score at baseline or who report struggling to imagine vivid future imagery), for example the exercises could focus more on the detail and clarity of the image and the homework task could include generating a vivid image to the recalled memory.

Two participants showed no therapeutic gains (ID2\&3) in depressive symptoms, which is consistent with response rates from more intensive psychological interventions (Goodyer et al. 2016). There are several explanations for this, including compliance with the homework tasks and history of mental health difficulties and previous interventions. ID3 showed poor compliance with the MEST and positive data $\log$ (completing 2 of 21 days) whilst ID2 showed better compliance, the app did not work on her phone (due to a technical problem) and so it was unclear when she was completing the memories (i.e. whether she was completing them daily or all at once). Both participants had significant mental health histories and at least 2 years of previous psychological therapy, and so are perhaps less likely to benefit from a brief intervention. Given their histories, these participants may have benefitted from an extended version of the intervention. For example, the negative images that these two participants chose were (anecdotally) less emotionally evocative than the other participants. This may have reflected their greater caution in sharing, given previous negative experiences of interventions and/or due to the limited and planned nature of the intervention. Participant 2 had the lowest score for positive future imagery and so it could equally 
Table 6 Changes in positive and negative affect ratings during memory recall task

\begin{tabular}{|c|c|c|c|c|c|c|c|c|c|c|c|c|}
\hline & & \multicolumn{9}{|c|}{ Participant number } & \multirow[t]{2}{*}{ Mean } & \multirow[t]{2}{*}{ SD } \\
\hline & & 1 & 2 & 3 & 4 & 5 & 6 & 7 & 8 & 9 & & \\
\hline \multicolumn{13}{|l|}{ Positive affect } \\
\hline \multirow{3}{*}{$\begin{array}{l}\text { Change scores } \\
\text { following } \\
\text { memory } \\
\text { recall }\end{array}$} & Pre change in ratings & 2.25 & 1.75 & -0.5 & -3.5 & 1.25 & 0.75 & -0.25 & 1.75 & 1.25 & 0.53 & 1.77 \\
\hline & Post change in ratings & -0.5 & 0.75 & 1 & 0.25 & 0.25 & 0.25 & -0.25 & 1 & 1.5 & 0.47 & 0.64 \\
\hline & Difference & -2.75 & -1 & 1.5 & 3.75 & -1 & -0.5 & 0 & -0.75 & 0.25 & -0.056 & -1.83 \\
\hline \multicolumn{13}{|l|}{ Negative affect } \\
\hline \multirow{3}{*}{$\begin{array}{l}\text { Change scores } \\
\text { following } \\
\text { memory } \\
\text { recall }\end{array}$} & Pre change in ratings & -3.25 & -2.5 & 0.75 & -0.75 & -0.5 & -1.25 & 0 & -1.25 & -1 & -1.08 & 1.21 \\
\hline & Post change in ratings & -2 & -1.5 & -0.25 & -1 & 0 & -0.25 & -0.5 & -0.25 & 0 & -0.64 & 0.71 \\
\hline & Difference & 1.25 & 1 & -1 & -0.25 & 0.5 & 1 & -0.5 & 1 & 1 & 0.44 & 0.82 \\
\hline
\end{tabular}

be that she would have benefitted from focusing on positive future images rather than the other components. Indeed, in our consultation with lived experience representatives who have received multiple therapies, they have suggested positive future imagery as a valuable target and one that has not been targeted in their previous experience of therapy. Further larger scale studies would be valuable in deciphering what predicts response to this imagery-based intervention. In terms of lack of change on other measures, the participants at one of the schools (ID1-4) were significantly affected by a terrorist attack that took place in London between the last intervention session and the post assessment. It is likely that the CRIES post assessment scores for these four participants (ID1-4) are biased by this event.

There are several limitations to this study, most notably the design and small sample size. The next step is to run a feasibility RCT to further investigate whether it is possible to run an RCT in a school setting and to assess acceptability. This single case series followed a design similar to previous research (e.g. Frets et al. 2014; Ritter and Stangier 2016) and was designed to be completed within a school term so that participants did not experience a significant break in the intervention due to school holidays. However, the design for reducing confounds was not optimal. It was not possible to have an extended baseline phase, which is recommended in single subject designs. Therefore, the current design cannot rule out spontaneous recovery or whether improvement was due to non-specific therapist factors (e.g. empathy and listening skills). A randomised multiple baseline design with weekly measurement (e.g. Dunn et al. 2019a, b) or a design that allowed collection of additional baseline data would have been preferable (Kratochwill et al. 2010). However, these designs are difficult to achieve within school-settings/ terms. We, therefore, selected the current design to maximise our principal aim, which was to assess feasibility and to inform the methodology for a future RCT, rather than to provide evidence for the specificity of the intervention. Checks were carried out on levels of change from screening to assessment which suggests that levels of depression were largely stable (for 2 weeks) before starting the intervention. As we conceived this study as an initial investigation to inform subsequent clinical trials, rather than a clinical trial itself, we did not pre-register it on a clinical trials registry. However, in retrospect, some form of pre-registration would have been preferable as this can benefit all study types.

In terms of feasibility and acceptability of recruitment strategies, we cannot know why participants did not respond to the invitation to take part in the research. Future trials could include a process evaluation to understand factors that may be influencing the decision to take part (or not) in the research. As we took an integrative approach to developing this complex intervention, we cannot know which mechanisms are driving the observed changes. A process evaluation that can provide rich detail on participant experience of the proposed therapeutic mechanisms, and investigating (in a larger trial) which cognitive mechanisms moderate change in which clinical measures, would help to unpack these findings. Another limitation is that a diagnostic interview was not conducted and so it is unclear whether these young people would meet criteria for depression. This was following advice from consultation with service-users and teachers. This also reflects clinical practice in UK settings, where clinical decisions are made based on symptom severity (according to self-report) and not diagnoses, adding pragmatic validity.

\section{Conclusions}

This study provides initial evidence that the intervention is acceptable to participants and leads to a reduction in depressive symptoms, with changes in some targeted psychological 


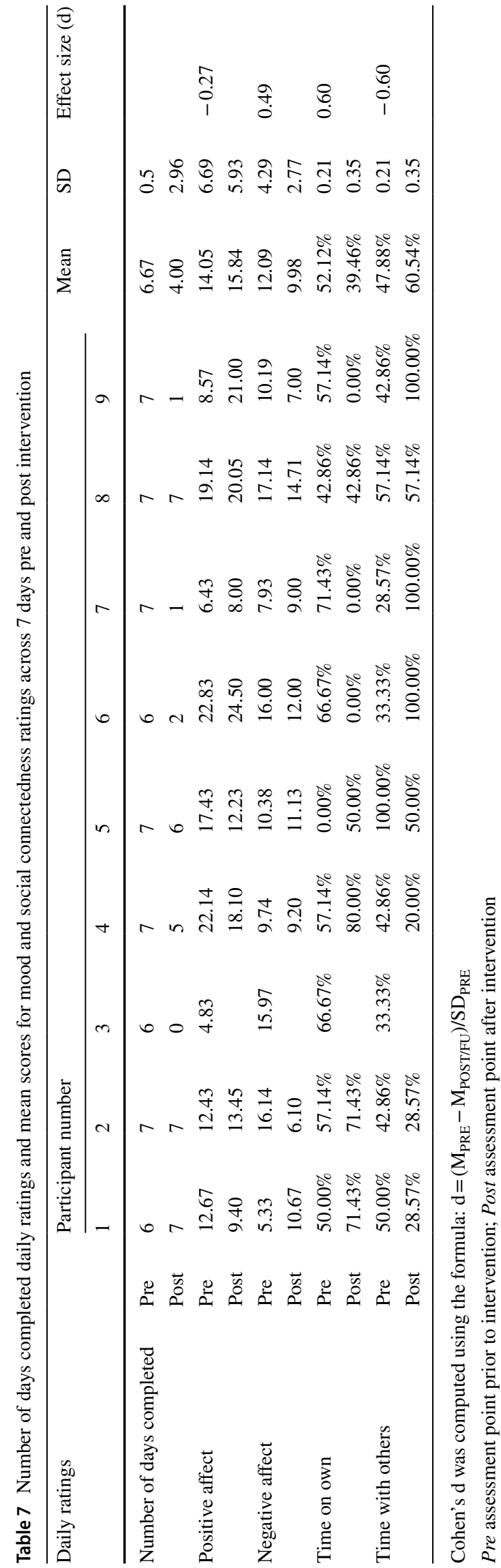

mechanisms. Future randomised controlled trials are indicated to assess the intervention against an appropriate control group.

Funding This study represents independent research from a Clinical Doctoral Research Fellowship (Dr Victoria Pile, ICACDRF-2015-01-007) supported by the National Institute for Health Research and Health Education England. The views expressed in this publication are those of the authors and not necessarily those of the NHS, NIHR, Health Education England or the Department of Health and Social Care.

Data Availability The datasets generated and analysed during the current study are available in Mendeley Data, https://doi.org/10.17632/ bkdzk4gk6k.2.

\section{Compliance with Ethical Standards}

Conflict of Interest Victoria Pile, Patrick Smith, Mary Leamy, Abigail Oliver, Simon E. Blackwell, Richard Meiser-Stedman, Barnaby D. Dunn, Emily A. Holmes, Jennifer Y. F. Lau declare that they have no conflict of interest with respect to this publication.

Ethical Approval All procedures performed in studies involving human participants were in accordance with the ethical standards of the institutional and/or national research committee and with the 1964 Helsinki declaration and its later amendments or comparable ethical standards.

Animal Rights Statements No animal studies were carried out by the authors for this article.

Informed Consent Informed consent was obtained from all individual participants included in the study.

Open Access This article is licensed under a Creative Commons Attribution 4.0 International License, which permits use, sharing, adaptation, distribution and reproduction in any medium or format, as long as you give appropriate credit to the original author(s) and the source, provide a link to the Creative Commons licence, and indicate if changes were made. The images or other third party material in this article are included in the article's Creative Commons licence, unless indicated otherwise in a credit line to the material. If material is not included in the article's Creative Commons licence and your intended use is not permitted by statutory regulation or exceeds the permitted use, you will need to obtain permission directly from the copyright holder. To view a copy of this licence, visit http://creativecommons.org/licenses/by/4.0/.

\section{References}

Abela, J. R. Z., Vanderbilt, E., \& Rochon, A. (2004). A test of the integration of the response styles and social support theories of depression in third and seventh grade children. Journal of Social and Clinical Psychology, 23(5), 653-674. https://doi.org/10.1521/ jscp.23.5.653.50752.

Andersen, S. L., \& Teicher, M. H. (2008). Stress, sensitive periods and maturational events in adolescent depression. Trends in Neurosciences, 31(4), 183-191.

Anderson, R. J., Dewhurst, S. A., \& Nash, R. A. (2012). Shared cognitive processes underlying past and future thinking: The impact 
of imagery and concurrent task demands on event specificity. Journal of Experimental Psychology: Learning, Memory, and Cognition, 38, 356-365.

Angold, A., Costello, E. J., Messer, S. C., Pickles, A., Winder, F., \& Silver, D. (1995). The development of a short questionnaire for use in epidemiological studies of depression in children and adolescents. International Journal of Methods in Psychiatric Research, 5, 237-249.

Birmaher, B., \& Brent, D. A. (2007). Practice parameter for the assessment and treatment of children and adolescents with depressive disorders. Journal of the American Academy of Child and Adolescent Psychiatry, 46(11), 1503-1526. https://doi.org/10.1097/ chi.0b013e318145ae1c.

Birmaher, B., Khetarpal, S., Brent, D., Cully, M., Balach, L., Kaufman, J., et al. (1997). The Screen for Child Anxiety Related Emotional Disorders (SCARED): Scale construction and psychometric characteristics. Journal of the American Academy of Child and Adolescent Psychiatry, 36(4), 545-553. https://doi.org/10.1097/00004 583-199704000-00018.

Blackwell, S. E., Browning, M., Mathews, A., Pictet, A., Welch, J., Davies, J., et al. (2015). Positive imagery-based cognitive bias modification as a web-based treatment tool for depressed adults: A randomized controlled trial. Clinical Psychological Science, 3(1), 91-111. https://doi.org/10.1177/2167702614560746.

Blackwell, S. E., \& Holmes, E. A. (2017). Brightening the day with flashes of positive mental imagery: A case study of an individual with depression. Journal of Clinical Psychology, 75(3), 1-11. https://doi.org/10.1002/jclp.22455.

Bos, A. E. R., Huijding, J., Muris, P., Vogel, L. R. R., \& Biesheuvel, J. (2010). Global, contingent and implicit self-esteem and psychopathological symptoms in adolescents. Personality and Individual Differences, 48(3), 311-316. https://doi.org/10.1016/j. paid.2009.10.025.

Brewin, C. R. (2006). Understanding cognitive behaviour therapy: A retrieval competition account. Behaviour Research and Therapy, 44(6), 765-784. https://doi.org/10.1016/j.brat.2006.02.005.

Brewin, C. R., Wheatley, J., Patel, T., Fearon, P., Hackmann, A., Wells, A., et al. (2009). Imagery rescripting as a brief stand-alone treatment for depressed patients with intrusive memories. Behaviour Research and Therapy, 47(7), 569-576. https://doi.org/10.1016/j. brat.2009.03.008.

Burnett Heyes, S., Lau, J. Y. F., \& Holmes, E. A. (2013). Mental imagery, emotion and psychopathology across child and adolescent development. Developmental Cognitive Neuroscience, 5, 119-133. https://doi.org/10.1016/j.den.2013.02.004.

Burnett Heyes, S., Pictet, A., Mitchell, H., Raeder, S. M., Lau, J. Y. F., Holmes, E. A., et al. (2017). Mental imagery-based training to modify mood and cognitive bias in adolescents: Effects of valence and perspective. Cognitive Therapy and Research, 41(1), 73-88. https://doi.org/10.1007/s10608-016-9795-8.

Calear, A. L., \& Christensen, H. (2010). Systematic review of schoolbased prevention and early intervention programs for depression. Journal of Adolescence, 33(3), 429-438. https://doi.org/10.1016/j. adolescence.2009.07.004.

Campbell, J. D., Trapnell, P. D., Heine, S. J., Katz, I. M., Lavallee, L. F., \& Lehman, D. R. (1996). Self-concept clarity: Measurement, personality correlates, and cultural boundaries. Journal of Personality and Social Psychology, 70(6), 141-156. https://doi. org/10.1037/0022-3514.70.6.1114.

Chang, E. C. (2001). Life stress and depressed mood among adolescents: Examining a cognitive-affective mediation model. Journal of Social and Clinical Psychology, 20(3), 416-429. https://doi. org/10.1521/jscp.20.3.416.22301.

Cohen, J. (1988). Statistical power analysis for the behavioral sciences (2nd ed.). Hillsdale, NJ: Erlbaum.
Conway, M. A., \& Pleydell-Pearce, C. W. (2000). The construction of autobiographical memories in the self-memory system. Psychological Review, 107(2), 261-288.

Cook, M. N., Peterson, J., \& Sheldon, C. (2009). Adolescent depression: An update and guide to clinical decision making. Psychiatry, 6(9), 17-31.

Craig, P., Dieppe, P., Macintyre, S., Michie, S., Nazareth, I., \& Petticrew, M. (2008). Developing and evaluating complex interventions: New guidance. London: Medical Research Council.

Dalgleish, T., \& Werner-Seidler, A. (2014). Disruptions in autobiographical memory processing in depression and the emergence of memory therapeutics. Trends in Cognitive Sciences, 18(11), 596-604. https://doi.org/10.1016/j.tics.2014.06.010.

Dunn, B. D., Mahen, H. O., Wright, K., \& Brown, G. (2019a). A commentary on research rigour in clinical psychological science: How to avoid throwing out the innovation baby with the research credibility bath water in the depression field. Behaviour Research and Therapy, 120(May), 103417. https://doi.org/10.1016/j. brat.2019.103417.

Dunn, B. D., Widnall, E., Reed, N., Owens, C., Campbell, J., \& Kuyken, W. (2019b). Bringing light into darkness: A multiple baseline mixed methods case series evaluation of Augmented Depression Therapy (ADepT). Behaviour Research and Therapy, 120, 103418. https://doi.org/10.1016/j.brat.2019.103418.

Ekkers, W., Korrelboom, K., Huijbrechts, I., Smits, N., Cuijpers, P., \& Van Der Gaag, M. (2011). Behaviour Research and Therapy Competitive Memory Training for treating depression and rumination in depressed older adults: A randomized controlled trial. Behaviour Research and Therapy, 49(10), 588-596. https://doi. org/10.1016/j.brat.2011.05.010.

Fombonne, E., Wostear, G., Cooper, V., Harrington, R., \& Rutter, M. (2001). The Maudsley long-term follow-up of child and adolescent depression: 2. Suicidality, criminality and social dysfunction in adulthood. The British Journal of Psychiatry, 179(3), 218-223. https://doi.org/10.1192/bjp.179.3.218.

Frets, P. G., Kevenaar, C., \& Van Der Heiden, C. (2014). Imagery rescripting as a stand-alone treatment for patients with social phobia: A case series. Journal of Behavior Therapy and Experimental Psychiatry, 45(1), 160-169. https://doi.org/10.1016/j.jbtep .2013.09.006

Gadeikis, D., Bos, N., Schweizer, S., Murphy, F., \& Dunn, B. (2017). Engaging in an experiential processing mode increases positive emotional response during recall of pleasant autobiographical memories. Behaviour Research and Therapy, 92, 68-76. https:// doi.org/10.1016/j.brat.2017.02.005.

Gee, B., Reynolds, S., Carroll, B., Orchard, F., Clarke, T., Martin, D., et al. (2020a). Practitioner review: Effectiveness of indicated school-based interventions for adolescent depression and anxiety-A meta-analytic review. Journal of Child Psychology and Psychiatry. https://doi.org/10.1111/jcpp.13209.

Gee, B., Wilson, J., Clarke, T., Farthing, S., Carroll, B., Jackson, C., et al. (2020b). Review: Delivering mental health support within schools and colleges-A thematic synthesis of barriers and facilitators to implementation of indicated psychological interventions for adolescents. Child and Adolescent Mental Health. https://doi. org/10.1111/camh.12381.

Gibbs, B. R., \& Rude, S. S. (2004). Overgeneral autobiographical memory as depression vulnerability. Cognitive Therapy and Research, 28(4), 511-526. https://doi.org/10.1023/B:COTR.0000045561 $.72997 .7 \mathrm{c}$

Goodyer, I. M., Reynolds, S., Barrett, B., Byford, S., Dubicka, B., Hill, J., et al. (2016). Cognitive behavioural therapy and short-term psychoanalytical psychotherapy versus a brief psychosocial intervention in adolescents with unipolar major depressive disorder (IMPACT): A multicentre, pragmatic, observer-blind, randomised 
controlled superiori. The Lancet Psychiatry, 0366(16), 1-11. https ://doi.org/10.1016/S2215-0366(16)30378-9.

Gulliver, A., Griffiths, K. M., \& Christensen, H. (2010). Perceived barriers and facilitators to mental health help-seeking in young people: A systematic review. BMC Psychiatry, 10, 113.

Health Committee. (2014). House of commons. Children's and adolescents' mental health and CAMHS. London: The Stationary Office.

Hirsch, C. R., Clark, D. M., \& Mathews, A. (2006). Imagery and interpretations in social phobia: Support for the combined cognitive biases hypothesis. Behavior Therapy, 37(3), 223-236. https://doi. org/10.1016/j.beth.2006.02.001.

Hirsch, C. R., Clark, D. M., Mathews, A., \& Williams, R. (2003). Selfimages play a causal role in social phobia. Behaviour Research and Therapy, 41(8), 909-921.

Hitchcock, C., Gormley, S., Rees, C., Rodrigues, E., Gillard, J., Panesar, I., et al. (2018). A randomised controlled trial of Memory Flexibility training (MemFlex) to enhance memory flexibility and reduce depressive symptomatology in individuals with Major Depressive Disorder. Behaviour Research and Therapy, 110, 22-30. https://doi.org/10.31234/OSF.IO/VYST6.

Hitchcock, C., Hammond, E., Rees, C., Panesar, I., Watson, P., Werner-Seidler, A., et al. (2015). Memory Flexibility training (MemFlex) to reduce depressive symptomatology in individuals with major depressive disorder: Study protocol for a randomised controlled trial. Trials, 16(1), 1-8. https://doi.org/10.1186/ s13063-015-1029-y.

Hitchcock, C., Nixon, R. D. V., \& Weber, N. (2014). A review of overgeneral memory in child psychopathology. British Journal of Clinical Psychology, 53(2), 170-193. https://doi.org/10.1111/ bjc. 12034.

Holmes, E. A., Blackwell, S. E., Burnett Heyes, S., Renner, F., \& Raes, F. (2016). Mental imagery in depression: Phenomenology, potential mechanisms, and treatment implications. Annual Review of Clinical Psychology, 12, 249-280. https://doi. org/10.1146/annurev-clinpsy-021815-092925.

Holmes, E. A., Ghaderi, A., Harmer, C. J., Ramchandani, P. G., Cuijpers, P., Morrison, A. P., et al. (2018). The Lancet Psychiatry Commission on psychological treatments research in tomorrow's science. The Lancet Psychiatry, 5(3), 237-286. https:// doi.org/10.1016/S2215-0366(17)30513-8.

Holmes, E. A., Hales, S. A., Young, K., \& Di Simplicio, M. (2019). Imagery-based cognitive therapy for bipolar disorder and mood instability. New York: Guilford Press.

Holmes, E. A., Lang, T. J., Moulds, M. L., \& Steele, A. M. (2008). Prospective and positive mental imagery deficits in dysphoria. Behaviour Research and Therapy, 46(8), 976-981. https://doi. org/10.1016/j.brat.2008.04.009.

Holmes, E. A., Mathews, A., Dalgleish, T., \& Mackintosh, B. (2006). Positive interpretation training: Effects of mental imagery versus verbal training on positive mood. Behavior Therapy, 37(3), 237-247. https://doi.org/10.1016/j.beth.2006.02.002.

Jacobson, N. S. Y., \& Truax, P. (1991). Clinical significance: A statistical approach to defining meaningful change in psychotherapy research. Journal of Consulting and Clinical Psychology, 59(1), 12-19. https://doi.org/10.1037/0022-006X.59.1.12.

Korrelboom, K., Maarsingh, M., \& Huijbrechts, I. (2012). Competitive Memory Training (COMET) for treating low self-esteem in patients with depressive disorders: A randomised clinical trial. Depression and Anxiety, 29, 102-110. https://doi.org/10.1002/ da.20921.

Kosslyn, S. M., Ganis, G., \& Thompson, W. L. (2001). Neural foundations of imagery. Nature Reviews: Neuroscience, 2, 635-642.

Kratochwill, T. R., Hitchcock, J., Horner, R. H., Levin, J. R., Odom, S. L., Rindskopf, D. M., et al. (2010). Single-case designs technical documentation. Retrieved May 20, 2020 from What
Works Clearinghouse website. https://ies.ed.gov/ncee/wwc/pdf/ wwc_scd.pdf.

Kuyken, W., \& Dalgleish, T. (2011). Overgeneral autobiographical memory in adolescents at risk for depression. Memory, 19, 241-250. https://doi.org/10.1080/09658211.2011.554421.

Kuyken, W., Howell, R., \& Dalgleish, T. (2006). Overgeneral autobiographical memory in depressed adolescents with, versus without, a reported history of trauma. Journal of Abnormal Psychology, 115(3), 387-396. https://doi. org/10.1037/0021-843X.115.3.387.

Madore, K. P., Gaesser, B., \& Schacter, D. L. (2014). Constructive episodic simulation: Dissociable effects of a specificity induction on remembering, imagining, and describing in young and older adults. Journal of Experimental Psychology: Learning Memory and Cognition, 40(3), 609-622. https://doi.org/10.1037/a0034885.

Meiser-Stedman, R., Dalgleish, T., Yule, W., \& Smith, P. (2012). Intrusive memories and depression following recent non-traumatic negative life events in adolescents. Journal of Affective Disorders, 137(1-3), 70-78. https://doi.org/10.1016/j.jad.2011.12.020.

Morina, N., Deeprose, C., Pusowski, C., Schmid, M., \& Holmes, E. A. (2011). Prospective mental imagery in patients with major depressive disorder or anxiety disorders. Journal of Anxiety Disorders, 25(8), 1032-1037. https://doi.org/10.1016/j.janxdis.2011.06.012.

Morina, N., Lancee, J., \& Arntz, A. (2017). Imagery rescripting as a clinical intervention for aversive memories: A meta-analysis. Journal of Behavior Therapy and Experimental Psychiatry, 55, 6-15. https://doi.org/10.1016/j.jbtep.2016.11.003.

Morley, S., \& Dowzer, C. N. (2014). Manual for the Leeds reliable change indicator: Simple excel applications for the analysis of individual patient and group data (pp. 1-13). Leeds: University of Leeds.

Neshat-Doost, H. T., Dalgleish, T., Yule, W., Kalantari, M., Ahmadi, S. J., Dyregrov, A., et al. (2012). Enhancing autobiographical memory specificity through cognitive training: An intervention for depression translated from basic science. Clinical Psychological Science, 1(1), 84-92. https://doi.org/10.1177/21677 02612454613.

Pearson, J., Naselaris, T., Holmes, E. A., \& Kosslyn, S. M. (2015). Mental imagery: Functional mechanisms and clinical applications. Trends in Cognitive Sciences, 19(10), 590-602. https:// doi.org/10.1016/j.tics.2015.08.003.

Perrin, S., Meiser-Stedman, R., \& Smith, P. (2005). The Children's Revised Impact of Event Scale (CRIES): Validity as a screening instrument for PTSD. Behavioural and Cognitive Psychotherapy, 33(04), 487. https://doi.org/10.1017/S1352465805002419.

Pictet, A., Coughtrey, A. E., Mathews, A., \& Holmes, E. A. (2011). Fishing for happiness: The effects of generating positive imagery on mood and behaviour. Behaviour Research and Therapy, 49(12), 885-891. https://doi.org/10.1016/j. brat.2011.10.003.

Pile, V., \& Lau, J. Y. F. (2018). Looking forward to the future: Impoverished vividness for positive prospective events characterises low mood in adolescence. Journal of Affective Disorders, 238, 269-276. https://doi.org/10.1016/j.jad.2018.05.032.

Raes, F., Williams, J. M. G., \& Hermans, D. (2009). Reducing cognitive vulnerability to depression: A preliminary investigation of MEmory Specificity Training (MEST) in inpatients with depressive symptomatology. Journal of Behavior Therapy and Experimental Psychiatry, 40(1), 24-38. https://doi.org/10.1016/j.jbtep .2008.03.001

Rasmussen, K. W., \& Berntsen, D. (2014). "I can see clearly now": The effect of cue imageability on mental time travel. Memory and Cognition, 42(7), 1063-1075. https://doi.org/10.3758/s1342 1-014-0414-1.

Renner, F., Ji, J. L., Pictet, A., Holmes, E. A., \& Blackwell, S. E. (2017). Effects of engaging in repeated mental imagery of future 
positive events on behavioural activation in individuals with major depressive disorder. Cognitive Therapy and Research, 41(3), 369-380. https://doi.org/10.1007/s10608-016-9776-y.

Ritter, V., \& Stangier, U. (2016). Seeing in the Mind's eye: Imagery rescripting for patients with body dysmorphic disorder. A single case series. Journal of Behavior Therapy and Experimental Psychiatry, 50, 187-195. https://doi.org/10.1016/j.jbtep .2015.07.007.

Rosenberg, M. (1965). Society and the adolescent self-image. Princeton, NJ: Princeton University Press.

Schacter, D. L., Addis, D. R., \& Buckner, R. L. (2007). Remembering the past to imagine the future: The prospective brain. Nature Reviews Neuroscience, 8(9), 657-661. https://doi. org/10.1080/08995600802554748.

Secretary of State for Health and Secretary of State for Education. (2017). Transforming children and young people's mental health provision: A Green Paper. https://assets.publishing .service.gov.uk/government/uploads/system/uploads/attachment _data/file/664855/Transforming_children_and_young_peopl e_s_mental_health_provision.pdf.

Simmons, J. P., Nelson, L. D., \& Simonsohn, U. (2012). A 21 word solution. https://doi.org/10.2139/ssrn.2160588.

Smith, P., Scott, R., Eshkevari, E., Jatta, F., Leigh, E., Harris, V., et al. (2015). Computerised CBT for depressed adolescents: Randomised Controlled Trial. Behaviour Research and Therapy, 73, 104-110. https://doi.org/10.1016/j.brat.2015.07.009.

Stober, J. (2000). Prospective cognitions in anxiety and depression: Replication and methodological extension. Cognition and Emotion, 9931, 37-41. https://doi.org/10.1080/02699930050117693.

Torkan, H., Blackwell, S. E., Holmes, E. A., Kalantari, M., NeshatDoost, H. T., Maroufi, M., et al. (2014). Positive imagery cognitive bias modification in treatment-seeking patients with major depression in Iran: A pilot study. Cognitive Therapy and Research, 38(2), 132-145. https://doi.org/10.1007/s1060 8-014-9598-8.

van Minnen, A., Wessel, I., Verhaak, C., \& Smeenk, J. (2005). The relationship between autobiographical memory specificity and depressed mood following a stressful life event: A prospective study. The British Journal of Clinical Psychology, 44(Pt 3), 405-415. https://doi.org/10.1348/014466505X29648.

Wenze, S. J., \& Miller, I. W. (2010). Use of ecological momentary assessment in mood disorders research. Clinical Psychology Review, 30(6), 794-804. https://doi.org/10.1016/j. cpr.2010.06.007.

Werner-Seidler, A., Hitchcock, C., Bevan, A., McKinnon, A., Gillard, J., Dahm, T., et al. (2018). A cluster randomized controlled platform trial comparing group MEmory specificity training (MEST) to group psychoeducation and supportive counselling (PSC) in the treatment of recurrent depression. Behaviour Research and Therapy, 105, 1-9. https://doi.org/10.1016/j. brat.2018.03.004.

Werner-Seidler, A., \& Moulds, M. L. (2012). Mood repair and processing mode in depression. Emotion, 12(3), 470-478. https:// doi.org/10.1037/a0025984.

Werner-seidler, A., Perry, Y., Calear, A. L., Newby, J. M., \& Christensen, H. (2017). School-based depression and anxiety prevention programs for young people: A systematic review and meta-analysis. Clinical Psychology Review, 51, 30-47. https:// doi.org/10.1016/j.cpr.2016.10.005.

Wheatley, J., Brewin, C. R., Patel, T., Hackmann, A., Wells, A., Fisher, P., et al. (2007). "I'll believe it when I can see it": Imagery rescripting of intrusive sensory memories in depression. Journal of Behavior Therapy and Experimental Psychiatry, 38(4), 371-385. https://doi.org/10.1016/j.jbtep 2007.08.005.

Wild, J., \& Clark, D. M. (2011). Imagery rescripting of early traumatic memories in social phobia. Cognitive and Behavioral Practice, 18(4), 433-443. https://doi.org/10.1016/j.cbpra .2011 .03 .002

Wild, J., Hackmann, A., \& Clark, D. M. (2008). Rescripting early memories linked to negative images in social phobia: A pilot study. Behavior Therapy, 39(1), 47-56. https://doi. org/10.1016/j.beth.2007.04.003.

Williams, A. D., \& Moulds, M. L. (2007). An investigation of the cognitive and experiential features of intrusive memories in depression. Memory, 15(8), 912-920. https://doi. org/10.1080/09658210701508369.

Williams, J. M. G., Barnhofer, T., Crane, C., Herman, D., Raes, F., Watkins, E., et al. (2007). Autobiographical memory specificity and emotional disorder. Psychological Bulletin, 133(1), 122-148. https://doi.org/10.1037/0033-2909.133.1.122.

Williams, J. M. G., \& Broadbent, K. (1986). Autobiographical memory in suicide attempters. Journal of Abnormal Psychology, 95(2), 144-149. https://doi.org/10.1037/0021-843X.95.2.144.

Williams, J. M. G., Ellis, N. C., Tyers, C., Healy, H., Rose, G., \& Macleod, A. K. (1996). The specificity of autobiographical memory and imageability of the future. Memory \& Cognition, 24(1), 116-125. https://doi.org/10.3758/BF03197278.

Wood, A., Kroll, L., Moore, A., \& Harrington, R. (1995). Properties of the mood and feelings questionnaire in adolescent psychiatric outpatients: A research note. Journal of Child Psychology and Psychiatry, and Allied Disciplines, 36(2), 327-334. https://doi. org/10.1111/j.1469-7610.1995.tb01828.x.

Wright, B., Tindall, L., Littlewood, E., Adamson, J., Allgar, V., Bennett, S., et al. (2014). Computerised cognitive behaviour therapy for depression in adolescents: Study protocol for a feasibility randomised controlled trial. British Medical Journal Open. https://doi.org/10.1136/bmjopen-2014-006488.

Zisook, S., Rush, A. J., Lesser, I., Wisniewski, S. R., Trivedi, M., Husain, M. M., et al. (2007). Preadult onset vs. adult onset of major depressive disorder: A replication study. Acta Psychiatrica Scandinavica, 115(3), 196-205. https://doi.org/10.111 $1 / \mathrm{j} .1600-0447.2006 .00868$.x.

Publisher's Note Springer Nature remains neutral with regard to jurisdictional claims in published maps and institutional affiliations. 